\title{
Advanced duodenal neoplasia and carcinoma in familial adenomatous polyposis: outcomes of surgical management
}

\author{
Fábio Guilherme Campos ${ }^{1}$, Carlos Augusto Real Martinez ${ }^{2}$, Leonardo Alfonso Bustamante Lopez ${ }^{1}$, \\ Danilo Toshio Kanno ${ }^{3}$, Sérgio Carlos Nahas ${ }^{1}$, Ivan Cecconello ${ }^{1}$ \\ ${ }^{1}$ Gastroenterology Department, Hospital das Clínicas, University of São Paulo Medical School, São Paulo, Brazil; ${ }^{2}$ Department of Surgery, Campinas \\ State University, UNICAMP, São Paulo, Brazil; ${ }^{3}$ San Francisco University, Bragança Paulista, Brazil \\ Contributions: (I) Conception and design: FG Campos, CA Martinez; (II) Administrative support: None; (III) Provision of study materials or patients: \\ None; (IV) Collection and assembly of data: None; (V) Data analysis and interpretation: DT Kanno, LA Bustamante Lopez; (VI) Manuscript writing: \\ All authors; (VII) Final approval of manuscript: All authors. \\ Correspondence to: Fábio Guilherme Campos. Rua Padre João Manoel, 222-Cj 120-Cerqueira César, CEP 01411-000, São Paulo, SP, Brazil. \\ Email: fgmcampos@terra.com.br.
}

Background: In addition to the presence of neoplasia in the colon and rectum, patients with familial adenomatous polyposis (FAP) may develop numerous polyps and carcinoma within the upper gastrointestinal tract.

Methods: The aim of the present paper was to review the incidence advanced duodenal polyposis or cancer and their surgical outcomes. A retrospective review of patients' records from our department was performed. Information was retrieved from a prospective collected data, including clinical (gender, age, family history), endoscopic [association with colorectal cancer (CRC), polyposis severity, age at diagnosis] and surgical management (age, time from the index surgery, type of procedure, morbidity). Duodenal adenomatosis at the time of surgery was classified according to Spigelman stages.

Results: In a group of 145 FAP patients, 8 (5.5\%) had been surgically treated for duodenal advanced neoplasia [3] or cancer [5]. There were included 2 women and 6 men whose first endoscopic examination and diagnosis of advanced neoplasia/cancer was made at median ages of 47.3 [28-63] and 51.8 years, respectively. Duodenal carcinomas occurred later (55.8 years) when compared to advanced adenomatosis (45.3 years). Three patients were diagnosed due to symptoms, while the others were detected under endoscopic surveillance. Age interval between FAP treatment and duodenal neoplasia diagnosis was 15.3 years [0-47]. All but one patient underwent duodenopancreatectomy (DP). Two from the 7 patients undergoing DP died, one from pulmonary embolism 30 days after surgery and the other from recurrent T4N0 duodenal tumor. Thus, major operative morbidity and mortality were $12.5 \%$.

Conclusions: In this single-center Brazilian series of FAP patients: (I) advanced duodenal neoplasia or cancer requiring surgery occurred in $5.5 \%$ of patients; (II) when reaching the fifth decade of life, patients should be carefully evaluated to diagnose and treat early lesions; (III) in spite of the technical complexity of DP, operative morbidity is acceptable in experienced hands; and (IV) continuous surveillance is necessary during follow-up.

Keywords: Familial adenomatous polyposis (FAP); adenomas; duodenum; adenomatosis; pancreaticoduodenectomy; surveillance

Submitted May 18, 2017. Accepted for publication Jul 19, 2017.

doi: 10.21037/jgo.2017.09.03

View this article at: http://dx.doi.org/10.21037/jgo.2017.09.03 


\section{Introduction}

Familial adenomatous polyposis (FAP) is a rare hereditary multi-system disorder (1:8,300 live births) leading to the development of multiple colorectal polyps that predispose to a high risk of colorectal cancer (CRC). Throughout time, the early names of this syndrome (familial polyposis coli, familial adenomatosis coli) didn't recognize the importance of other extracolonic manifestations such as duodenal adenomatosis (1).

As a consequence of the widespread indication of prophylactic colectomy, mortality from CRC has decreased substantially over the years (2-4), making duodenal cancer and desmoid tumors important causes of death in FAP patients (5-9).

Duodenal adenomas develop in the second and third parts of duodenum, including the periampullary region (10). In FAP, the cumulative lifetime risks for adenoma may approach $100 \%$, while $3-5 \%$ may progress to adenocarcinoma (11-13). The recognition of this increased risk as well as the poor prognosis of duodenal cancer and the morbidity associated with a subsequent duodenal resection have stimulated attempts to early diagnosis and treatment in this patient population $(14,15)$.

As duodenal adenomas progress slowly to carcinoma (16), it is justified to develop aggressive and effective endoscopic surveillance programs to identify any precursor lesion (17). Local management of duodenal polyposis is associated with high rates of recurrence, although it may postpone cancer development. Thus, endoscopic or surgical management of patients diagnosed with large polyps, high-grade dysplasia or severe duodenal polyposis turned to be important preventive tools to decrease cancer deaths in FAP patients $(1,18)$. Otherwise, patients diagnosed with duodenal cancer should undergo radical pancreaticoduodenectomy that may carry substantial morbidity and mortality rates $(19,20)$.

So far, the development of duodenal carcinoma during the evolution of FAP patients has deserved scarce attention in Brazilian publications (21-23). Thus, we decided to investigate the prevalence, clinical features and surgical outcomes of FAP duodenal advanced adenomas and carcinoma that have been diagnosed and treated in the greatest public hospital in Brazil.

Appreciation of these outcomes may give us an insight into the advantages, benefits and risks of complex procedures usually performed to prevent cancer or treat duodenal neoplasia in the setting of FAP.

\section{Methods}

The charts of 145 FAP patients treated in colorectal unit during from July 1958 to December 2016 were reviewed. In this group, we identified patients diagnosed with duodenal advanced lesions or carcinoma, focusing on those who have undergone surgery.

Information was retrieved from data including clinical evaluation (gender, age at FAP diagnosis, age at duodenal operation, family history), endoscopic assessment (association with CRC, colorectal polyposis severity) and surgical management (age, time from the index surgery, type of colorectal resection, surgical procedure for duodenal lesion, 30 days postoperative morbidity and mortality).

During the last ten years, upper digestive lesions were assessed by front-view and/or side-view endoscopy. Endoscopic profile regarding duodenal adenomatosis (usually at the time of surgery) was classified according to Spigelman stages. Advanced ampullary or duodenal neoplasia was categorized as lesions greater than $10 \mathrm{~mm}$, presenting villous histology or with high-grade dysplasia). When diagnosed, assessment by endoscopic ultrasound (EUS) was also performed prior to endoscopic resection, in order to carefully evaluate dimensions, chances of polypectomy or need for subsequent surgical resection.

Duodenal cancer cases were identified according to the presentation diagnosis (detected at surveillance endoscopy or due to clinical symptoms). Similarly, lesions were classified as ampullary or duodenal (non-ampullary duodenum). Surgical outcomes, causes of death, survival and follow-up details were raised to address the effectiveness of different management strategies.

\section{Results}

In a group of $145 \mathrm{FAP}$ patients treated in this period, 8 $(5.5 \%)$ met the inclusion criteria of this study as they had been surgically treated for duodenal advanced neoplasia $(\mathrm{n}=3 ; 2.1 \%)$ or cancer $(\mathrm{n}=5 ; 3.4 \%)$. Clinical and surgical data concerning previous FAP treatment are shown in Table 1. Two women and 6 men with endoscopic features of classic FAP had undergone ileal-rectal anastomosis (IRA) or proctocolectomy (PC) at a mean age of 36.5 years (17-50 years), most of them [7] presenting family history of polyposis. CRC was present in the colorectal resected specimen in three patients, two of which developed duodenal cancer. 
Table 1 Data regarding clinical features of FAP patients undergoing surgery for FAP and diagnosis of advanced duodenal adenoma or carcinoma

\begin{tabular}{lcccccc}
\hline Case & Sex & Age (years) & Familial history of FAP & CRC & Colon operation & Age at first endoscopy, years \\
\hline 1 & F & 17 & No & No & IRA & 40 \\
2 & M & 34 & Yes & Yes & PC + APR & 63 \\
3 & M & 40 & Yes & Yes & IPAA-C & 50 \\
4 & M & 39 & Yes & No & IRA-C & 36 \\
5 & M & 37 & Yes & No & IPAA-V & 50 \\
6 & M & 50 & Yes & Yes & IPAA-V & 48 \\
7 & F & 48 & Yes & No & IPAA-V & 28 \\
\hline
\end{tabular}

FAP, familial adenomatous polyposis; CRC, colorectal cancer; IRA, ileal-rectal anastomosis; PC, proctocolectomy.

Table 2 Data concerning diagnosis, pathology and outcomes of advanced duodenal adenoma and carcinoma

\begin{tabular}{|c|c|c|c|c|c|c|}
\hline Case & Diagnosis (age), years & Diagnosis (how) & Interval (y) & Local & Pathology TNM & Outcome \\
\hline 2 & 63 & Surveillance & 29 & $\mathrm{D}$ & Spigelman IV adenoma & Alive 66 months \\
\hline 3 & 60 & Weight loss & 20 & $D+P$ & Carcinoma T4NO & Dead 48 months \\
\hline 4 & 54 & Surveillance & 15 & $\mathrm{D}$ & Carcinoma T1N0 & Alive 96 months \\
\hline 6 & 53 & Surveillance & 3 & $D+P$ & Carcinoma T1NO & Dead 1 months \\
\hline 7 & 48 & Jaundice & 0 & $\mathrm{P}$ & Carcinoma T1No & Alive 60 months \\
\hline 8 & 28 & Surveillance & 0 & $\mathrm{D}$ & Spigelman IV adenoma & Alive 5 months \\
\hline
\end{tabular}

The first endoscopic examination was performed at a median age of 47.3 years (28-63 years), allowing the diagnosis of 2 patients with duodenal cancer (cases 4 and 6). Both patients had already been submitted to FAP surgery. All cases of advanced duodenal adenomas were detected at the first endoscopy ever performed.

Table 2 presents data regarding diagnosis and treatment of the duodenal lesions. Median age of diagnosis of advanced neoplasia or cancer was 51.8 years. However, the median age of patients with duodenal carcinomas was higher $(55.8$ $v s .45 .3$ years) when compared to advanced adenomatosis.

Three patients were diagnosed due to symptoms, while the others were detected under surveillance. Age interval between FAP treatment and duodenal neoplasia diagnosis was 15.3 [0-47] years. Two patients had their lesions diagnosed at the same time as the polyposis. Ampullary involvement was seen in 4 patients, 2 of them presenting jaundice, one complaining of weight loss and one other asymptomatic patient was diagnosed under surveillance.

All but one patient underwent duodenopancreatectomy (DP). This patient had an extensive Spigelman IV duodenal lesion and he refused endoscopic control or a major surgical procedure (Figure 1). For this reason, he underwent duodenotomy with local resection of the lesions. After a follow-up period of 61 months, endoscopy revealed duodenal recurrence. Two from the 7 patients undergoing DP died, one from pulmonary embolism 30 days after surgery and the other from recurrence of a T4N0 duodenal tumor. Thus, major operative morbidity and mortality were $12.5 \%$.

\section{Discussion}

Today it is well recognized that the relative risks of duodenal cancer (331 times) and ampullary carcinoma (124 times) are much greater among FAP patients in comparison to 
the general population [about $0.01-0.04 \%$ (24)]. Moreover, despite the high prevalence of duodenal polyps among FAP patients, the crude incidence of duodenal cancer varies from $0.7 \%$ to $5 \%$, as seen in Table 3 . This estimative clearly demonstrates that the malignant risk of duodenal adenomas is much lower when compared to colonic ones $(11,25,26)$.

One of the first reports in the literature found an incidence of $3.1 \%$ among 1,255 patients from ten registries (27). In a retrospective multicenter study from Japan, Yamaguchi et al. (6) reported 7 cases (2.8\%) among 247 FAP patients. The Dutch Registry found 18 cases $(1.7 \%)$ of duodenal

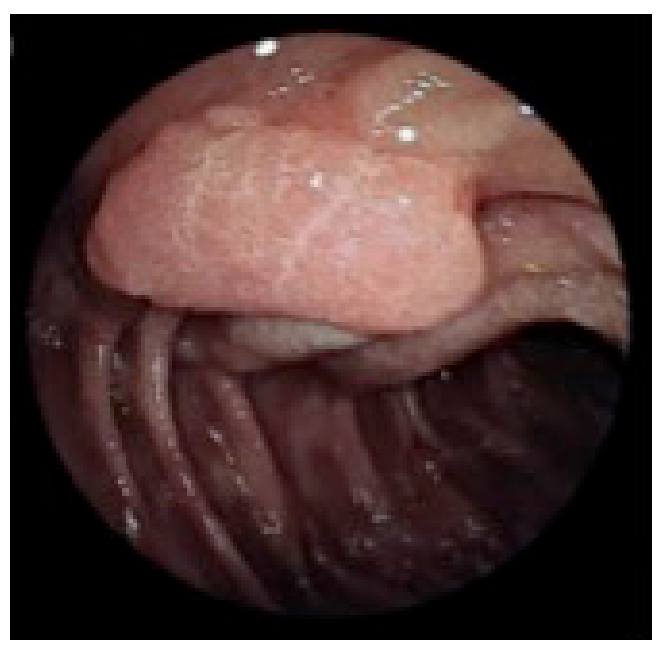

Figure 1 Spigelman IV duodenal lesion in FAP. FAP, familial adenomatous polyposis. cancer out of 1,066 patients during a 33-year period (17). Another important study registered a $1.9 \%$ incidence rate at the St Mark Hospital Polyposis Registry (15). In the present single-center study, we detected duodenal cancer in $3.4 \%$ of a FAP cohort that has been treated over five decades.

However, the cumulative risk at $60-70$ years has been estimated to reach $4.5 \%$ to $10 \%$ of FAP patients $(11,25,28,29)$. It has been demonstrated that duodenal cancer risk increases with age, time after FAP diagnosis and with progressive adenoma stage $(26,30,31)$.

While patients with less severe adenomatosis (stages 0-III) may develop duodenal cancer less frequently ( $0.7 \%$ of cases), stage IV patients are prone to a much greater risk (7-36\%) $(11,12,30)$. In this context, the Spigelman score has been widely adopted to guide surveillance frequency after 25-30 years of age, as well as to help with the therapeutic decisions process (6). However, the identification of patients at risk remains a challenge, cause the progression between stages varies a lot $(1,32)$. In this sense, avoidance of progression to stage IV disease would lessen duodenal cancer risk, and that is the reason why screening for duodenal carcinoma has been currently recommended.

Worsening of adenomatosis with advancing age is a slow process (33) and age has been incriminated as the most important risk factor for duodenal cancer (31). However, environmental and hereditary factors may also affect cancer incidence in FAP cohorts. For example, when compared to Western countries, the incidence of gastric and duodenal cancers has been reported to be higher and lower in Asia, respectively $(18,34)$. Furthermore, length of follow-up,

Table 3 Prevalence of duodenal cancer in polyposis registries reported in the literature

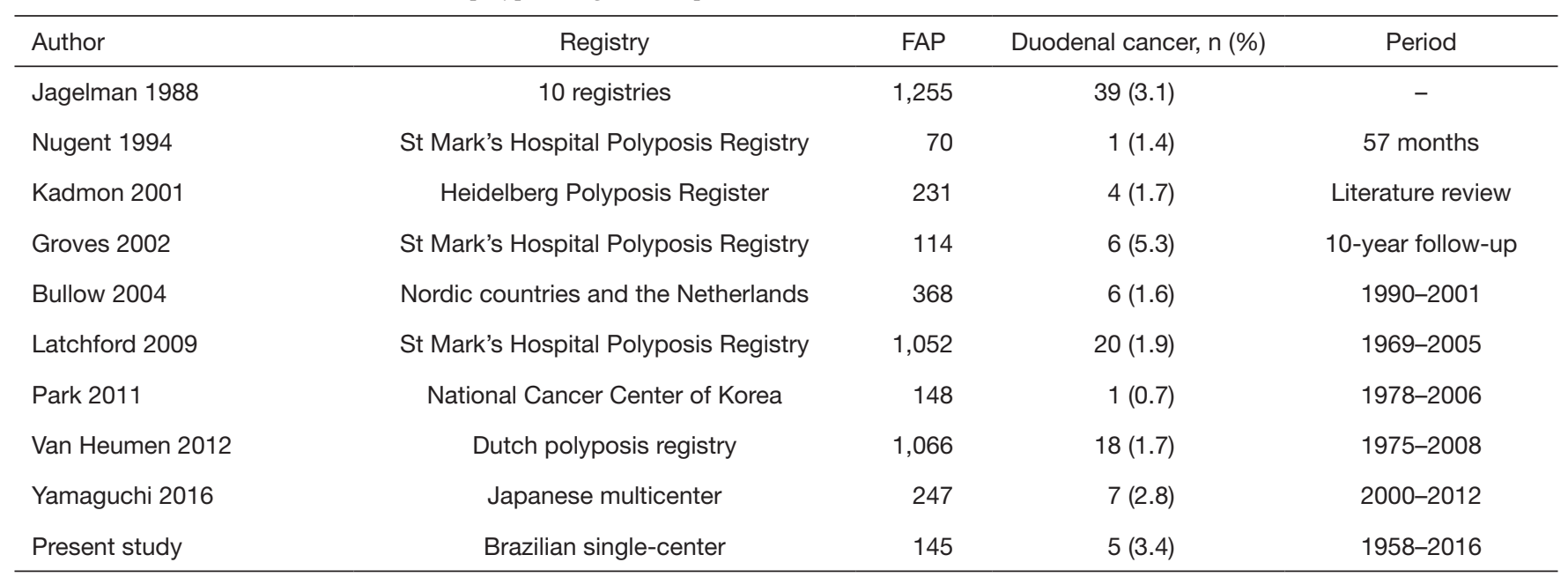

FAP, familial adenomatous polyposis. 
endoscopic techniques (use of side-viewing endoscopy, high resolution endoscopy, chromoendoscopy), strategies for prevention, frequent endoscopic resection of at risk lesions, ampullary localization have also been incriminated to influence incidence rates (23).

Usually, duodenal polyps are more often recognized 10-20 years after the diagnosis of colonic polyposis $(35,36)$. In a survey among polyposis registries coordinated by the Leeds Castle Group, the mean age at the time of surgery for invasive carcinoma (53 years) was 10 years higher than that for severe polyposis (43 years) (20). Similarly, a nationwide study found mean ages of 53 [32-67] years among a group of 18 duodenal cancers and 48 [31-69] years in those with benign adenomatosis (17). In the present series, duodenal neoplasia was detected 15 years after FAP treatment, and advanced adenomatosis patients were also operated earlier than cancers ( 45.3 vs. 55.8 years, respectively).

But eventually, symptoms associated with a duodenal lesion may favor a more precocious detection. Besides pancreatitis, ampullary lesions may also cause obstructive jaundice (6). Three of our patients were diagnosed due to symptoms, while the others were detected under surveillance. Ampullary involvement was seen in 4 patients, 2 of them presenting jaundice, one complaining of weight loss and one other asymptomatic patient was diagnosed under surveillance. Differently from the Dutch series (17), we diagnosed only one patient with an advanced duodenal cancer (T4, T2 and T1N0 lesions). In their study, a curative resection was not possible in almost one-half of the patients due to an advanced staging.

CRC was present in the colorectal resected specimen in 3 patients, 2 of which developed duodenal cancer. This interesting association has already been noticed, leading the authors to recommend patients diagnosed with CRC at previous initial surgery to follow the recommended surveillance protocols (17).

Numerous prospective series have evaluated the natural history of duodenal adenomas $(11,30,37)$. One important issue is that ampullary and duodenal diseases should be considered separately. It has been shown that more than half of FAP patients may harbor ampullary adenomas even in cases with normal endoscopic appearance (37). Ampullary lesions are considered to have a greater risk of carcinoma progression when compared to non-ampullary adenomas, especially those greater than $1 \mathrm{~cm}$, with villous histology or moderate/severe dysplasia $(15,38)$. This difference is the basis why the Spigelman classification may not eventually evaluate an individual's risk accurately.
Management of polyps and cancer is accomplished by endoscopic and surgical procedures. Traditionally, while low-risk lesions may still benefit from less complex conservative approaches, more advanced lesions may require surgical excision if endoscopic control seems ineffective or not possible. In the case of duodenal adenomatosis, an optimum management must balance the risk of an invasive carcinoma, potential endoscopic complications and surgical morbidity.

Despite that, both endoscopic evaluation and management present some limitations. Biopsies taken from Spigelman IV lesions may not always reveal the presence of a carcinoma, so the score assessed in resected specimens may be higher than that obtained preoperatively (20). Furthermore, high-resolution endoscopy and narrowband imaging did not improve malignant estimates over Spigelman score (39). Moreover, a large number of lesions and their sessile appearance may add technical problems and difficult endoscopic management by argon plasma coagulation or resection (23). Finally, recurrence rate of duodenal lesions after endoscopic intervention remains high (30).

Timing and choice for surgery should take into account several features such as age and health status, previous abdominal surgery, severity and evolution of duodenal adenomatosis, previous treatments and staging (17). Such features may help decide between local (duodenotomy with polypectomy and/or ampullectomy) or more radical procedures (pancreas and pylorus sparing duodenectomy, cephalic pancreaticoduodenectomy).

Duodenal carcinoma may be associated with poor prognosis (20). Thus, an effective surveillance is justified to identify risk lesions before malignant transformation occurs. For this reason, some centers offer surgical treatment right after the diagnosis of an advanced benign disease (stages III or IV) (1).

This aggressive approach aims to remove suspicious lesions in order to prevent their growing and to maximize patient outcomes. In spite of this, a surgical approach in this situation may raise some controversy and cause duodenal resection presented significant morbidity (1).

Eventually, resection through surgical duodenotomy may be an option in difficult or potential dangerous cases, due to its low morbidity. Transduodenal resection has been exceptionally recommended because recurrence is common (32-43\%), besides it may provide temporary relief of cancer threat and thus postpone definitive surgery $(12,32,40)$. We had the opportunity to resect a $3 \mathrm{~cm}$ villous adenoma in a 
37 years man in whom endoscopic resection was considered too risky. Recurrence was detected only 18 months after duodenotomy.

However, curative management of duodenal and periampullary malignancies is surgical, unless patients are considered unfit or refuse a major surgery. Potential candidates should receive proper information and complete preoperative evaluation to assess surgical risks factors (1). In this setting, staging with computed tomography and EUS is crucial.

In the present series, most patients [7] were submitted to pancreatoduodenectomy (PD) (Whipple's operation), 5 of them for cancer and 2 involving exclusively the Vater papilla. This operation and also the pancreas-sparing duodenectomy (PSD) may be potentially curative, besides the operative risks.

Fortunately, all patients undergoing duodenalpancreatic resections in our Department were operated by a group of specialized and experienced surgeons. For this reason, morbidity was too low in our series. Besides that, one patient died from pulmonary embolism thirty days after PD.

PSD has been indicated in FAP patients with adenomatosis, because it has been associated with low mortality (around 2.3\%) (30). According to the surgeons from these five centers, this procedure facilitates endoscopic follow-up and requires less anastomosis. In a multicentric review performed in Netherlands from 2000-2007, survival, morbidity and mortality rates were comparable between pylorus-preserving total duodenectomy and PD (41). Other studies have also documented similar rates of morbidity (38-60\%) and mortality (0-12\%) in FAP patients undergoing PSD or PD $(42,43)$.

However, sometimes morbidity in FAP patients may be higher than that observed in non-FAP cohorts. This finding has been attributed to previous surgery adhesions and desmoplastic changes that occur in this group. Another possible reason is that the normal soft pancreas and nondilated pancreatic and biliary ductal system could lead to anastomotic leak more easily in FAP patients (1).

Besides the associated morbidity, extensive procedures do not entirely eliminate the risk of cancer. Endoscopic followup has documented recurrent adenomas and even cancer in the proximal small bowel after duodenectomy $(20,44,45)$. This issue has been documented after most procedures. In a questionnaire sent to Leeds Castle Polyposis Group members, the authors documented adenomas recurrence after ampullectomy (6/8), duodenectomy (17/21) or pancreato-duodenectomy (6/25), but not after PSD (6 patients) (20). Thus, upper gastrointestinal surveillance and chemopreventive measures should be continued even after extensive surgical procedures. Unfortunately, improvement of clinical outcomes after chemoprevention have been disappointing so far, with no consistent reduction of polyp burden after treatment for months (46). Further investigations should address long-term effectiveness by controlling side effects and improving clinical outcomes in a larger population.

\section{Conclusions}

After reaching the fifth decade of life, FAP patients must be advised about the risks of developing a duodenal cancer. In fact, surveillance should start after 25 years of age to prevent cancer by controlling advanced lesions and helping to postpone a more radical surgery. When necessary, radical procedures such as PD may be performed with acceptable morbidity by skilled surgical teams. In our experience, advanced duodenal neoplasia or cancer requiring surgery occurred in $5.5 \%$ of patients. Continuous surveillance is necessary during follow-up.

Papilla and duodenal lesions may deserve different considerations in terms of carcinogenic risks and should be staged differently. In the future, molecular investigations on this field will probably help categorize risk groups, indicate prognosis and help with surgical decision.

\section{Acknowledgements}

None.

\section{Footnote}

Conflicts of Interest: The authors have no conflicts of interest to declare.

Ethical Statement: The study was approved by the Gastroenterology Department Ethics Committee in Hospital das Clínicas (MemoCAPPesq 049/17) and written informed consent was obtained from all patients.

\section{References}

1. Skipworth JR, Morkane C, Raptis DA, et al. Pancreaticoduodenectomy for advanced duodenal and ampullary adenomatosis in familial adenomatous polyposis. 
HPB (Oxford) 2011;13:342-9.

2. Bülow S. Clinical features in familial polyposis coli. Results of the Danish Polyposis Register. Dis Colon Rectum 1986;29:102-7.

3. Järvinen HJ, Husa A, Aukee S, et al. Finnish registry for familial adenomatosis coli. Scand J Gastroenterol 1984;19:941-6.

4. Vasen HF, Griffioen G, Offerhaus GJ, et al. The value of screening and central registration of families with familial adenomatous polyposis. A study of 82 families in The Netherlands. Dis Colon Rectum 1990;33:227-30.

5. de Campos FG, Perez RO, Imperiale AR, et al. Evaluating causes of death in familial adenomatous polyposis. J Gastrointest Surg 2010;14:1943-9.

6. Yamaguchi T, Ishida H, Ueno H, et al. Upper gastrointestinal tumours in Japanese familial adenomatous polyposis patients. Jpn J Clin Oncol 2016;46:310-5.

7. Iwama T, Tamura K, Morita T, et al. A clinical overview of familial adenomatous polyposis derived from the database of the Polyposis Registry of Japan. Int J Clin Oncol 2004;9:308-16.

8. Belchetz LA, Berk T, Bapat BV, et al. Changing causes of mortality in patients with familial adenomatous polyposis. Dis Colon Rectum 1996;39:384-7.

9. Galle TS, Juel K, Bulow S. Causes of death in familial adenomatous polyposis. Scand J Gastroenterol 1999;34:808-12.

10. Jung I, Gurzu S, Turdean GS. Current status of familial gastrointestinal polyposis syndromes. World J Gastrointest Oncol 2015;7:347-55.

11. Bülow S, Björk J, Christensen IJ, et al. Duodenal adenomatosis in familial adenomatous polyposis. Gut 2004;53:381-6.

12. Brosens LA, Keller JJ, Offerhaus GJ, et al. Prevention and management of duodenal polyps in familial adenomatous polyposis. Gut 2005;54:1034-43.

13. Vasen HF, Bülow S, Myrhøj T, et al. Decision analysis in the management of duodenal adenomatosis in familial adenomatous polyposis. Gut 1997;40:716-9.

14. Serrano PE, Grant RC, Berk TC, et al. Progression and Management of Duodenal Neoplasia in Familial Adenomatous Polyposis: A Cohort Study. Ann Surg 2015;261:1138-44.

15. Latchford AR, Neale KF, Spigelman AD, et al. Features of duodenal cancer in patients with familial adenomatous polyposis. Clin Gastroenterol Hepatol 2009;7:659-63.

16. Spigelman AD, Talbot IC, Penna C, et al. Evidence for adenoma-carcinoma sequence in the duodenum of patients with familial adenomatous polyposis. The Leeds Castle Polyposis Group (Upper Gastrointestinal Committee). J Clin Pathol 1994;47:709-10.

17. van Heumen BW, Nieuwenhuis MH, van Goor H, et al. Surgical management for advanced duodenal adenomatosis and duodenal cancer in Dutch patients with familial adenomatous polyposis: a nationwide retrospective cohort study. Surgery 2012;151:681-90.

18. Park SY, Ryu JK, Park JH, et al. Prevalence of gastric and duodenal polyps and risk factors for duodenal neoplasm in korean patients with familial adenomatous polyposis. Gut Liver 2011;5:46-51.

19. Komori S, Kawai M, Nitta T, et al. A case of carcinoma of the papilla of Vater in a young man after subtotal colectomy for familial adenomatous polyposis. World J Surg Oncol 2016;14:47.

20. de Vos tot Nederveen Cappel WH, Järvinen HJ, Björk $\mathrm{J}$, et al. Worldwide survey among polyposis registries of surgical management of severe duodenal adenomatosis in familial adenomatous polyposis. Br J Surg 2003;90:705-10.

21. Leal RF, Ayrizono Mde L, Coy CS, et al. Gastroduodenal polyposis in patients with familiar adenomatous polyposis after rectocolectomy. Arq Gastroenterol 2007;44:133-6.

22. Campos FG, Habr-Gama A, Kiss DR, et al. Extracolonic manifestations of familial adenomatous polyposis: incidence and impact on the disease outcome. Arq Gastroenterol 2003;40:92-8.

23. Campos FG, Sulbaran M, Safatle-Ribeiro AV, et al. Duodenal adenoma surveillance in patients with familial adenomatous polyposis. World J Gastrointest Endosc 2015;7:950-9.

24. Sexe RB, Wade TP, Virgo KS, et al. Incidence and treatment of periampullary duodenal cancer in the U.S. veteran patient population. Cancer 1996;77:251-4.

25. Björk J, Akerbrant H, Iselius L, et al. Periampullary adenomas and adenocarcinomas in familial adenomatous polyposis: cumulative risks and APC gene mutations. Gastroenterology 2001;121:1127-35.

26. Saurin JC, Gutknecht C, Napoleon B, et al. Surveillance of duodenal adenomas in familial adenomatous polyposis reveals high cumulative risk of advanced disease. J Clin Oncol 2004;22:493-8.

27. Jagelman DG, DeCosse JJ, Bussey HJ. Upper gastrointestinal cancer in familial adenomatous polyposis. Lancet 1988;1:1149-51.

28. Nugent KP, Spigelman AD, Williams CB, et al. Surveillance of duodenal polyps in familial adenomatous polyposis: progress report. J R Soc Med 1994;87:704-6. 
29. Kadmon M, Tandara A, Herfarth C. Duodenal adenomatosis in familial adenomatous polyposis coli. A review of the literature and results from the Heidelberg Polyposis Register. Int J Colorectal Dis 2001;16:63-75.

30. Groves CJ, Saunders BP, Spigelman AD, et al. Duodenal cancer in patients with familial adenomatous polyposis (FAP): results of a 10 year prospective study. Gut 2002;50:636-41.

31. Vasen HF, Möslein G, Alonso A, et al. Guidelines for the clinical management of familial adenomatous polyposis (FAP). Gut 2008;57:704-13.

32. Heiskanen I, Kellokumpu I, Järvinen H. Management of duodenal adenomas in 98 patients with familial adenomatous polyposis. Endoscopy 1999;31:412-6.

33. Matsumoto T. Natural history of ampullary adenoma in familial adenomatous polyposis: reconfirmation of benign nature during extended surveillance. Am J Gastroenterol 2000;95:1557-62.

34. Dekker E, Boparai KS, Poley JW, et al. High resolution endoscopy and the additional value of chromoendoscopy in the evaluation of duodenal adenomatosis in patients with familial adenomatous polyposis. Endoscopy 2009;41:666-9.

35. Wallace $M H$, Phillips RK. Upper gastrointestinal disease in patients with familial adenomatous polyposis. Br J Surg 1998;85:742-50.

36. Sarre RG, Frost AG, Jagelman DG, et al. Gastric and duodenal polyps in familial adenomatous polyposis: a prospective study of the nature and prevalence of upper gastrointestinal poly. Gut 1987;28:306-14.

37. Burke CA, Beck GJ, Church JM, et al. The natural history of untreated duodenal and ampullary adenomas in patients with familial adenomatous polyposis followed in an endoscopic surveillance program. Gastrointest Endosc 1999;49:358-64.

38. Cordero-Fernández C, Garzón-Benavides M, PizarroMoreno A, et al. Gastroduodenal involvement in patients with familial adenomatous polyposis. Prospective study

Cite this article as: Campos FG, Martinez CA, Bustamante Lopez LA, Kanno DT, Nahas SC, Cecconello I. Advanced duodenal neoplasia and carcinoma in familial adenomatous polyposis: outcomes of surgical management. J Gastrointest Oncol 2017;8(5):877-884. doi: 10.21037/jgo.2017.09.03 of the nature and evolution of polyps: evaluation of the treatment and surveillance methods applied. Eur J Gastroenterol Hepatol 2009;21:1161-7.

39. Lopez-Ceron M, van den Broek FJ, Mathus-Vliegen EM, et al. The role of high-resolution endoscopy and narrowband imaging in the evaluation of upper GI neoplasia in familial adenomatous polyposis. Gastrointest Endosc 2013;77:542-50.

40. Johnson MD, Mackey R, Brown N, et al. Outcome based on management for duodenal adenomas: sporadic versus familial disease. J Gastrointest Surg 2010;14:229-35.

41. de Castro SM, van Eijck CH, Rutten JP, et al. Pancreaspreserving total duodenectomy versus standard pancreatoduodenectomy for patients with familial adenomatous polyposis and polyps in the duodenum. Br J Surg 2008;95:1380-6.

42. Mackey R, Walsh RM, Chung R, et al. Pancreassparing duodenectomy is effective management for familial adenomatous polyposis. J Gastrointest Surg 2005;9:1088-93.

43. Gallagher MC, Shankar A, Groves CJ, et al. Pyloruspreserving pancreaticoduodenectomy for advanced duodenal disease in familial adenomatous polyposis. Br J Surg 2004;91:1157-64.

44. Murakami Y, Uemura K, Sasaki M, et al. Duodenal cancer arising from the remaining duodenum after pyloruspreserving pancreatoduodenectomy for ampullary cancer in familial adenomatous polyposis. J Gastrointest Surg 2005;9:389-92.

45. Ruo L, Coit DG, Brennan MF, et al. Long-term followup of patients with familial adenomatous polyposis undergoing pancreaticoduodenal surgery. J Gastrointest Surg 2002;6:671-5.

46. Samadder NJ, Neklason DW, Boucher KM, et al. Effect of Sulindac and Erlotinib vs Placebo on Duodenal Neoplasia in Familial Adenomatous Polyposis: A Randomized Clinical Trial. JAMA 2016;315:1266-75. 